\title{
Identification of in vitro and in vivo phosphorylation sites in the catalytic subunit of the DNA-dependent protein kinase
}

 \\ Katheryn MEEK§, Dario R. ALESSI $\$$ and Susan P. LEES-MILLER ${ }^{\star} \dagger^{-1}$ \\ *Department of Biochemistry \& Molecular Biology, University of Calgary, 3330 Hospital Drive, Calgary, AB, T2N 4N1, Canada, †Department of Biological Sciences, \\ University of Calgary, 2500 University Drive NW, Calgary, AB, T2N 1N4, Canada, \$MRC Protein Phosphorylation Unit, School of Life Sciences, Division of Cell \\ Signalling, University of Dundee, Dundee DD1 5EH, U.K., and §Carcinogenesis Laboratory, Michigan State University, East Lansing, MI 48824-1302, U.S.A.
}

\begin{abstract}
The DNA-dependent protein kinase (DNA-PK) is required for the repair of DNA double-strand breaks (DSBs), such as those caused by ionizing radiation and other DNA-damaging agents. DNA-PK is composed of a large catalytic subunit (DNA-PKcs) and a heterodimer of $\mathrm{Ku} 70$ and $\mathrm{Ku} 80$ that assemble on the ends of double-stranded DNA to form an active serine/threonine protein kinase complex. Despite in vitro and in vivo evidence to support an essential role for the protein kinase activity of DNAPK in the repair of DNA DSBs, the physiological targets of DNA-PK have remained elusive. We have previously shown that DNA-PK undergoes autophosphorylation in vitro, and that autophosphorylation correlates with loss of protein kinase activity and dissociation of the DNA-PK complex. Also, treatment of cells with the protein phosphatase inhibitor, okadaic acid, enhances DNA-PKcs phosphorylation and reduces DNA-PK
\end{abstract}

activity in vivo. Here, using solid-phase protein sequencing, MS and phosphospecific antibodies, we have identified seven in vitro autophosphorylation sites in DNA-PKcs. Six of these sites $\left(\mathrm{Thr}^{2609}, \mathrm{Ser}^{2612}, \mathrm{Thr}^{2620}, \mathrm{Ser}^{2624}, \mathrm{Thr}^{2638}\right.$ and $\left.\mathrm{Thr}^{2647}\right)$ are clustered in a region of 38 amino acids in the central region of the protein. Five of these sites $\left(\mathrm{Thr}^{2609}, \mathrm{Ser}^{2612}, \mathrm{Thr}^{2638}, \mathrm{Thr}^{2647}\right.$ and $\mathrm{Ser}^{3205}$ ) are conserved between six vertebrate species. Moreover, we show that DNA-PKcs is phosphorylated in vivo at $\mathrm{Thr}^{2609}$, $\mathrm{Ser}^{2612}$, $\mathrm{Thr}^{2638}$ and $\mathrm{Thr}^{2647}$ in okadaic acid-treated human cells. We propose that phosphorylation of these sites may play an important role in DNA-PK function.

Key words: autophosphorylation site, DNA double-strand break repair, non-homologous end-joining.

\section{INTRODUCTION}

The non-homologous end-joining (NHEJ) pathway is essential for the repair of ionizing radiation-induced DNA double-strand breaks (DSBs) in human cells (reviewed in $[1,2]$ ). Genetic studies have implicated several genes in this pathway, including XRCC7, XRCC5, XRCC6, XRCC4, DNL4 and Artemis [1-5]. These genes encode for the DNA-dependent protein kinase (DNA-PK) catalytic subunit (DNA-PKcs), Ku70, Ku80, XRCC4, DNA ligase IV and Artemis respectively [1-5].

Biochemical studies suggest that the first step in NHEJ is binding of the $\mathrm{Ku} 70 / 80$ heterodimer to the ends of DNA at the $\mathrm{DSB}$. Ku then translocates inwards a few bases, which serves to recruit DNA-PKcs. The protein kinase activity of DNA-PKcs is greatly enhanced by DNA-mediated association with the $\mathrm{Ku}$ heterodimer; thus assembly of the DNA-PKcs-Ku complex at the ends of DNA results in formation of a serine/threonine protein kinase holoenzyme, DNA-PK, that is tethered to the ends of the DNA at the site of the DNA DSB $[1,2,6]$. XRCC4 and DNA ligase IV form a tetrameric complex [7], which is also recruited to the repair complex, and is required for end joining. Artemis has recently been shown to possess both endo- and exo-nucleolytic activities, which may be important for processing DNA ends during NHEJ [5]. Experiments in cell-free extracts have revealed that $\mathrm{MgATP}$ is required for DNA-PK-dependent end joining in vitro $[8,9]$. DNA-PK-dependent DNA end joining is also inhibited by the fungal metabolite wortmannin $[8,9]$, an inhibitor of the protein kinase activity of DNA-PK $[10,11]$. These facts point to an essential role for the protein kinase activity of DNA-PK in NHEJ. Moreover, DNA-PKes that contains mutations in the protein kinase domain fails to restore efficient DNA DSB repair in cell lines that are deficient for DNA-PKcs, indicating that the protein kinase activity of DNAPK is essential for DNA DSB repair in vivo $[12,13]$. However, a clear demonstration of the downstream target or targets of DNA-PK has been lacking. Current models predict that DNAPKcs interacts with $\mathrm{Ku}$ at the site of a DNA DSB, and that this interaction results in increased protein kinase activity. Thus, DNA-PK-mediated phosphorylation of proteins that are assembled at the DNA DSB site may play an important role in NHEJ.

We and others have previously shown that, in vitro, DNA-PK phosphorylates many protein substrates, for example Hsp90 [14], p53 [15] and c-Jun [16], on serine or threonine residues that are followed by glutamine, i.e. an SQ or TQ motif. DNA-PK also shows a preference for SQ and TQ sequences in the context of synthetic peptides $[15,17]$. However, DNA-PK can also phosphorylate proteins at 'non-SQ' sites, with a preference for serine or threonine followed by a hydrophobic amino acid $[18,19]$. DNA-PKcs, Ku70, Ku80, XRCC4, DNA ligase IV and Artemis contain numerous SQ or TQ motifs. In addition, these proteins are intimately involved in NHEJ, and are present at the DNA break sites. They are therefore logical candidates for in vivo targets of DNA-PK. Previously, we have shown that DNAPKcs, Ku70 and Ku80 undergo DNA-PK-dependent phosphorylation in vitro [20,21]. Phosphorylation of DNA-PK in vitro results in a loss of protein kinase activity and dissociation of DNA-PKcs from DNA-bound $\mathrm{Ku}[21,22]$. Moreover, we have shown that DNA-PKcs, Ku70 and Ku80 are phosphorylated

Abbreviations used: DNA-PK, DNA-dependent protein kinase; DNA-PKcs, DNA-dependent protein kinase catalytic subunit; DSB, double-strand break; MALDI-TOF MS, matrix-assisted laser-desorption ionization-time-of-flight MS; NHEJ, non-homologous end joining.

1 To whom correspondence should be addressed (e-mail leesmill@ucalgary.ca) 
in vivo, and that conditions that promote hyperphosphorylation of DNA-PKcs and $\mathrm{Ku}$ in vivo lead to a reduction in DNA-PK kinase activity, suggesting that autophosphorylation may regulate DNA-PK activity in vivo [23]. In vivo phosphorylation of DNA-PKcs, Ku70 and Ku80 was enhanced when cells were treated with the protein phosphatase inhibitor okadaic acid, suggesting that DNA-PK phosphorylation in vivo is regulated by the activity of protein phosphatases [23].

As a first step towards elucidating the role of protein phosphorylation in NHEJ, we recently mapped DNA-PK phosphorylation sites in $\mathrm{Ku} 70$ and $\mathrm{Ku} 80$ [19]. Although recombinant $\mathrm{Ku} 70$ was phosphorylated at an SQ sequence in vitro $\left(\mathrm{Ser}^{51}\right)$, in the context of the $\mathrm{Ku} 70 / 80$ heterodimer the major phosphorylation site in $\mathrm{Ku} 70$ was $\mathrm{Ser}^{6}$, which is located in the amino acid sequence ESSY (phosphorylated amino acid underlined) [19]. Similarly, the major DNA-PK phosphorylation sites in Ku80 are $\mathrm{Ser}^{578}, \mathrm{Ser}^{580}$ and $\mathrm{Thr}^{715}$, none of which correspond to the 'typical' SQ/TQ motif [19]. Interestingly, the DNA-PK phosphorylation sites in $\mathrm{Ku} 70 / 80$ all lie in unique $\mathrm{N}$ - or C-terminal regions outside of the conserved DNA-binding core [24,25]. Here we have identified seven autophosphorylation sites in human DNA-PKcs (Thr ${ }^{2609}, \mathrm{Ser}^{2612}, \mathrm{Thr}^{2620}, \mathrm{Ser}^{2624}, \mathrm{Thr}^{2638}, \mathrm{Thr}^{2647}$ and $\mathrm{Ser}^{3205}$ ). Five of these sites correspond to SQ/TQ sites and two occur on serines that are followed by a hydrophobic amino acid. Six of the sites are tightly clustered within a 38-amino-acid region of the $469 \mathrm{kDa}$ DNA-PKcs polypeptide. Furthermore we show, using phosphospecific antibodies, that four of the sites $\left(\mathrm{Thr}^{2609}\right.$, $\mathrm{Ser}^{2612}$, $\mathrm{Thr}^{2638}$ and $\mathrm{Thr}^{2647}$ ) are phosphorylated in vivo in okadaic acid-treated cells.

\section{MATERIALS AND METHODS}

\section{Materials}

Okadaic acid, microcystin-LR and Zwittergent 3-16 were purchased from Calbiochem. BSA, PMSF, Tris base, EGTA, leupeptin, pepstatin, 4-vinylpyridine, $\alpha$-cinnamic acid and wortmannin were from Sigma. Calf thymus DNA was purchased from Aldrich. Dithiothreitol was from BDH. $\left[\gamma_{-}{ }^{32} \mathrm{P}\right] \mathrm{ATP}$ was from Perkin-Elmer Life Sciences.

\section{Identification of in vitro autophosphorylation sites on DNA-PKcs}

The DNA-PKes and $\mathrm{Ku}$ subunits of DNA-PK were purified from human placenta as described previously [21]. Purified DNAPKcs $(10 \mu \mathrm{g})$ and $\mathrm{Ku}(3.3 \mu \mathrm{g})$ proteins were incubated in $50 \mu \mathrm{l}$ of reaction mixture containing $25 \mathrm{mM}$ Hepes/ $\mathrm{NaOH}, \mathrm{pH} 7.5$, $100 \mathrm{mM} \mathrm{KCl}, 10 \mathrm{mM} \mathrm{MgCl}_{2}, 1 \mathrm{mM}$ dithiothreitol, $0.2 \mathrm{mM}$ EGTA, $0.1 \mathrm{mM}$ EDTA, $0.5 \mu \mathrm{M}$ microcystin-LR plus $10 \mu \mathrm{g} / \mathrm{ml}$ sonicated calf thymus DNA, and reactions were started by the addition of $0.25 \mathrm{mM}$ ATP containing stabilized $\left[\gamma-{ }^{32} \mathrm{P}\right]$ ATP (specific activity 500-1000 d.p.m./pmol). Aliquots were removed at timed intervals and analysed by SDS/PAGE and autoradiography to calculate the stoichiometry of phosphate incorporation and to determine that the reaction had achieved saturation. The reaction was terminated after $60 \mathrm{~min}$ by the addition of $1 \%$ SDS and $10 \mathrm{mM}$ dithiothreitol, and the sample was heated at $100{ }^{\circ} \mathrm{C}$ for $1 \mathrm{~min}$. After cooling, 4-vinylpyridine was added to a concentration of $0.5 \%(\mathrm{v} / \mathrm{v})$ and the samples were placed on a shaking platform for $30 \mathrm{~min}$ at room temperature to alkylate cysteine residues. Each reaction was subjected to electrophoresis on an $8 \%$ acrylamide/SDS gel and then analysed by autoradiography. The phosphorylated band corresponding to ${ }^{32} \mathrm{P}$-labelled DNA-PKcs was excised from the gel and cut into small pieces. The gel pieces were washed sequentially, for $15 \mathrm{~min}$ per wash, on a vibrating platform with $1 \mathrm{ml}$ of water, followed by $1 \mathrm{ml}$ of water/acetonitrile $(1: 1, \mathrm{v} / \mathrm{v}), 0.1 \mathrm{M}$ ammonium bicarbonate, $0.2 \mathrm{M}$ ammonium bicarbonate/acetonitrile $(1: 1, \mathrm{v} / \mathrm{v})$ and finally $100 \%$ acetonitrile. The gel pieces were dried in a rotary evaporator and incubated in $0.2 \mathrm{ml}$ of $50 \mathrm{mM}$ ammonium bicarbonate $/ 0.05 \%(\mathrm{w} / \mathrm{v})$ Zwittergent 3-16 containing $2 \mu \mathrm{g}$ of trypsin. After $16 \mathrm{~h}$, the supernatant was removed and the gel pieces were washed for $10 \mathrm{~min}$ in $0.2 \mathrm{ml}$ of $50 \mathrm{mM}$ ammonium bicarbonate $/ 0.05 \%(\mathrm{w} / \mathrm{v})$ Zwittergent 3-16/0.1\% (v/v) trifluoroacetic acid. The combined supernatants, which contained $>90 \%$ of the ${ }^{32} \mathrm{P}$ radioactivity, were chromatographed on a Vydac $\mathrm{C}_{18}$ column as described in the legend to Figure 1 (see below).

\section{Phosphopeptide sequence analysis}

${ }^{32}$ P-labelled peptides were analysed at the MRC Protein Phosphorylation Unit at the University of Dundee, Dundee, U.K., by matrix-assisted laser-desorption ionization-time-of-flight MS (MALDI-TOF MS) on a PerSeptive Biosystems Elite STR mass spectrometer (Framingham, MA, U.S.A), using $\alpha$-cyanocinnamic acid as the matrix. Spectra were obtained in both linear and reflector modes. Peptide masses obtained from MALDITOF mass spectra in the reflector mode are given as monoisotopic masses, while those obtained in the linear mode are given in average mass units. Mass values were used to search against the predicted masses of predicted DNA-PKcs tryptic peptides, and candidate peptides were identified. The site of phosphorylation in each HPLC-purified phosphopeptide was determined by solidphase Edman degradation of the peptide coupled to SequelonAA membrane (Milligen) on an Applied Biosystems 476A sequenator as described previously [26]. Some phosphopeptides were also analysed by electrospray MS on a Q-TOF2 mass spectrometer (Micromass, Altrincham, Cheshire, U.K.). Phosphoamino acid analysis was as described [27].

\section{Antibodies}

A monoclonal antibody to the C-terminus of DNA-PKcs (mAb 42-27) was as described previously [28]. Phosphospecific antibodies recognizing DNA-PKcs at $\mathrm{Thr}^{2609}, \mathrm{Ser}^{2612}, \mathrm{Thr}^{2620}, \mathrm{Thr}^{2638}$ and $\mathrm{Thr}^{2647}$ were raised in sheep against the following peptides: $\mathrm{Thr}^{2609}$, (K)(K)LTPMFVETQAS(R); $\mathrm{Ser}^{2612}$, (K)TQASQGTLQTR; Thr ${ }^{2620}$, (K)TRTQEGSLSAR; $\mathrm{Thr}^{2638}$, (K)GQIRATQQQHD; and $\mathrm{Thr}^{2647}$, (K)FTLTQTADGRS. The underlined residue in each peptide corresponds to phosphothreonine or phosphoserine. Amino acids in parentheses represent additional lysine or arginine residues that were added to the $\mathrm{N}$ - and/or C-terminus of the peptides to promote solubility. The peptide sequences correspond to residues 2602-2612, 2609-2619, 26182628, 2633-2643 and 2644-2654 of human DNA-PKcs respectively. Equal amounts of BSA-conjugated peptide and keyhole limpet haemocyanin-conjugated peptides were combined and used for immunization.

Each of the antisera was affinity purified on $\mathrm{CH}$-Sepharose (Amersham Biosciences) to which the corresponding phosphorylated peptide had been covalently coupled. The bound fraction was then passed through a second column of $\mathrm{CH}$-Sepharose to which the corresponding non-phosphorylated peptide had been coupled. Antisera that did not bind to the second column were selected. Secondary antibodies coupled to horseradish peroxidase (Pierce) raised against sheep IgG were used for immunoblotting.

\section{DNA-PK phosphorylation assays}

Purified DNA-PKcs (100 ng) and Ku70/80 (30 ng) were incubated in the presence of $50 \mathrm{mM}$ Hepes/ $\mathrm{NaOH}(\mathrm{pH} 7.5), 50 \mathrm{mM}$ $\mathrm{KCl}, 10 \mathrm{mM} \mathrm{MgCl}_{2}$ or $\mathrm{MnCl}_{2}$ (as indicated in Figure 4) and 




\section{Figure 1 Tryptic peptide map of ${ }^{32}$ P-labelled DNA-PKcs}

Autophosphorylated DNA-PKcs was separated by electrophoresis on an SDS/polyacrylamide gel and then digested with trypsin as described in the Materials and methods section. The resulting ${ }^{32}$ P-labelled peptides were chromatographed on a Vydac 218TP54 $\mathrm{C}_{18}$ column (Separations Group, Hesperia, CA, U.S.A.) equilibrated in 0.1\% (v/v) trifluoroacetic acid in water. The column was developed with a linear acetonitrile gradient (diagonal line) at a flow rate of $0.8 \mathrm{ml} / \mathrm{min}$, and fractions of $0.4 \mathrm{ml}$ were collected; $>80 \%$ of the radioactivity applied to the column was recovered in the fractions. Similar profiles were obtained in three separate experiments. The positions of the phosphopeptides termed $P_{1}-P_{6}$ are indicated.

$0.25 \mathrm{mM}$ unlabelled (non-radioactive) ATP, plus sonicated calf thymus DNA (at $10 \mu \mathrm{g} / \mathrm{ml}$ ). Samples were analysed by SDS/ PAGE on $8 \%$ acrylamide $/ 0.1 \%$ bisacrylamide gels followed by immunoblotting as described previously [21], and probed with phosphospecific and non-phosphospecific antibodies as described below.

\section{Cell culture and cell extracts}

Human lymphoblastoid cells (BT) were maintained in RPMI 1640 medium (Life Technologies) supplemented with $10 \%$ fetal calf serum in an atmosphere of $5 \% \mathrm{CO}_{2}$ [29]. Where indicated, logarithmic-phase cells $\left(1 \times 10^{6}\right.$ cells $/ 10 \mathrm{ml}$ dish $)$ were incubated in media containing okadaic acid at a $1 \mu \mathrm{M}$ final concentration. Okadaic acid was prepared in DMSO. For control incubations the corresponding volume of DMSO was added to the cells. Cells were harvested by centrifugation, washed twice in PBS, and lysed by incubation on ice for $1 \mathrm{~h}$ in lysis buffer $(50 \mathrm{mM}$ Tris $/ \mathrm{HCl}$, pH 8.0, 0.25 mM EDTA, 0.15 M NaCl and $1 \%$ (v/v) Nonidet P40). Lysates were then centrifuged at $10000 \mathrm{~g}$ for $10 \mathrm{~min}$ at $4{ }^{\circ} \mathrm{C}$. The supernatant was removed, snap-frozen in liquid nitrogen and stored at $-80{ }^{\circ} \mathrm{C}$. Protein concentrations were determined using a detergent-compatible dye-binding assay (Bio-Rad) with BSA as a standard.

\section{Immunoblotting}

For immunoblots of total cell lysates (see Figure 5, below), $100 \mu \mathrm{g}$ of protein was used. For purified DNA-PKcs (see Figures 3 and 4, below), $100 \mathrm{ng}$ of protein was used. Samples were subjected to SDS/PAGE and transferred to nitrocellulose membrane (Bio-Rad). For the phosphospecific DNA-PKcs antibodies, membranes were incubated in $25 \mathrm{mM}$ Tris/ $\mathrm{HCl}(\mathrm{pH} 7.5)$, $0.5 \mathrm{M} \mathrm{NaCl}, 0.5 \%$ (v/v) Tween-20 and $10 \%(\mathrm{w} / \mathrm{v})$ skimmed milk powder for $7 \mathrm{~h}$ at $4{ }^{\circ} \mathrm{C}$ in the presence of $2 \mu \mathrm{g} / \mathrm{ml}$ antiserum. Where indicated, phosphorylated (blocking peptide) or nonphosphorylated (control) peptide, corresponding to the antigen to which the antibody was raised, was included with the primary antibody at a final concentration of $10 \mu \mathrm{g} / \mathrm{ml}$. After probing with the phosphospecific antibodies, immunoblots were stripped and reprobed using a non-phosphospecific monoclonal antibody (mAb 42-27) [28] to the C-terminus of DNA-PKcs. Detection was performed using horseradish peroxidase-conjugated secondary antibodies and ECL (Amersham Biosciences).

\section{RESULTS}

\section{Identification of in vitro phosphorylation sites in DNA-PKcs}

Purified DNA-PKcs and Ku70/80 heterodimer were incubated with DNA as described in the Materials and methods section. Under these conditions, approx. $7 \mathrm{~mol}$ of phosphate were incorporated per mol of DNA-PKcs, suggesting that DNA-PKcs was phosphorylated at several sites in vitro. Reactions were terminated after $60 \mathrm{~min}$, and, after reduction and alkylation of cysteine residues, the proteins were separated by SDS/PAGE. Radioactively labelled DNA-PKcs was excised from the SDS/ PAGE gel, digested with trypsin and the released phosphopeptides were isolated by HPLC (see the Materials and methods section and legend to Figure 1). Over $90 \%$ of the radioactivity was released from the gel pieces by tryspin digestion. Six peaks of radioactivity that fractionated between 5 and $30 \%$ acetonitrile were resolved, labelled $\mathrm{P}_{1}-\mathrm{P}_{6}$ (Figure 1). A cluster of radioactive peaks that eluted from $30-50 \%$ acetonitrile was also observed; however, these peptides proved refractory to further purification, and were not studied further at this time. Each of the six phosphopeptides $\left(\mathrm{P}_{1}-\mathrm{P}_{6}\right)$ was next analysed by phosphoamino acid analysis, solid-phase Edman degradation and MS. 


\section{Table 1 Characterization of HPLC-purified phosphopeptides from a tryptic digest of in vitro-phosphorylated DNA-PKcs}

DNA-PKcs was phosphorylated and the phosphopeptides generated were purified on reversed-phase HPLC as described in the Materials and methods section. Six major peaks of radioactivity were detected $\left(\mathrm{P}_{1}-\mathrm{P}_{6}\right.$; Figure 1). Each phosphopeptide was analysed by phosphoamino acid analysis, solid-phase sequencing and MS as described in the text. Unless otherwise indicated, MS results are from MALDI-TOF MS in reflector mode, and are expressed as monoisotopic mass. In the column where peptide masses are given, the mass determined by MS is shown first, followed, in parentheses, by the theoretical peptide mass. In the final column, phosphorylated amino acids are underlined and the position of the phosphorylated amino acid is given in parentheses. MetSo, methionine sulphone; PAAA, phosphoamino acid analysis.

\begin{tabular}{|c|c|c|c|c|}
\hline Peptide & PAAA & $\begin{array}{l}\text { Cycle of radioactivity } \\
\text { release }\end{array}$ & $\begin{array}{l}\text { Peptide residue numbers, post-translational } \\
\text { modifications and peptide mass }\end{array}$ & Amino acid sequence \\
\hline$P_{1}$ & Ser & 5 & $2620-2628+\mathrm{PO}_{4} ; 1028.42^{\star}(1028.441)$ & TQEGSLSAR $\left(\operatorname{Ser}^{2624}\right)$ \\
\hline$P_{2}$ & Thr & 2 and 11 & $2637-2653+\mathrm{PO}_{4} ; 1997.8302(1997.9055)$ & ATQQQ̄HDFTLTQTAGDR (Thr ${ }^{2638}$ and Thr $^{2647}$ ) \\
\hline$P_{3}^{2}$ & Thr & 10 and 19 & $2629-2653+\mathrm{PO}_{4} / 2 \mathrm{PO}_{4} ; 2910.51 / 2988.93 \dagger(2907.1 / 2987.1)$ & WPVAGQIRATQ̄QQHDFTLTQTAGDR $\left(\operatorname{Thr}^{2638}\right.$ and Thr $\left.^{2647}\right)$ \\
\hline $\mathrm{P}_{4}$ & Ser/Thr & 11 and 14 & $2599-2619+\mathrm{PO}_{4} / 2 \mathrm{PO}_{4} ; 2392.74 / 2472.75 \dagger(2392.62 / 2472.62)$ & STVLTPMFVETQASQGTLQTR $\left(\operatorname{Th}^{2609}\right.$ and $\left.\mathrm{Se}^{2612}\right)$ \\
\hline$P_{5}^{4}$ & Ser/Thr & 11 and 14 & $2599-2619+\mathrm{PO}_{4}^{4}+$ MetSo; 2390.97 (2391.16) & STVLTPMFVET̄QĀ̄̄QGTLQTR (Thr $\mathrm{T}^{2609}$ and $\mathrm{Ser}^{2612}$ ) \\
\hline$P_{6}$ & Ser & 9 & $3197-3232+\mathrm{PO}_{4}^{4}+$ MetS0; 4197.84† (4197.55) & LTPLPEDNSMNNVD̄QDGDPSDRMEVQEQEEDISSLIR $\left(\mathrm{Ser}^{3205}\right)$ \\
\hline
\end{tabular}

* Mass was detected by electrospray MS on a Q-TOF2 instrument.

$\uparrow$ Average mass assigned from MALDI-TOF MS in the linear mode.

Phosphopeptide $\mathrm{P}_{1}$ contained only phosphoserine (Table 1, and results not shown). When analysed by Edman degradation, radioactivity was released in sequencer cycle 5 (Figure 2A). MALDI-TOF MS revealed an ion of mass 1028.42 (monoisotopic mass), which was consistent with the presence of the peptide TQEGSLSAR containing one phosphate group (Table 1). Further analysis of this peptide by electrospray on a Q-TOF2 mass spectrometer confirmed the presence of this sequence, and indicated phosphorylation at position 5 . We conclude that phosphopeptide $\mathrm{P}_{1}$ corresponds to amino acids 2620-2628 of DNA-PKcs, and is phosphorylated at $\operatorname{Ser}^{2624}$ (Table 1). Although $\mathrm{Ser}^{2624}$ is not followed by a glutamine and therefore does not conform to the previously identified SQ motif [15], it does resemble the 'S-hydrophobic' consensus identified in DNA-PK phosphorylation sites in $\mathrm{Ku} 70$ and $\mathrm{Ku} 80$ [19].

Phosphopeptide peak $\mathrm{P}_{2}$ was phosphorylated only at threonine (Table 1, and results not shown). Solid-phase Edman sequencing resulted in a major burst of radioactivity at cycle 2 and a smaller release at cycle 11 (Figure 2B). Using MALDI-TOF MS, a peptide of mass 1997.8302 (monoisotopic mass) was detected. Together, these data are consistent with the presence of a phosphopeptide corresponding to amino acids 2637-2653 of DNA-PKcs, which is phosphorylated predominantly at $\mathrm{Thr}^{2638}$ in the amino acid sequence ATQQQHD (Table 1). The solidphase Edman sequencing data (Figure $2 \mathrm{~B}$ ) suggest that $\mathrm{P}_{2}$ also contains a small amount of the same peptide in which $\mathrm{Thr}^{2647}$ (at position 11 of the peptide) is phosphorylated (Table 1). Both $\mathrm{Thr}^{2638}$ and $\mathrm{Thr}^{2647}$ are followed by glutamine, and thus conform to the typical TQ-type DNA-PK phosphorylation consensus.

Phosphopeptide peak $\mathrm{P}_{3}$ was also phosphorylated only on threonine (Table 1, and results not shown). Solid-phase Edman sequencing revealed a major phosphorylation site at position 10 , and a minor site at position 19 (Figure 2C). Two ions of average mass 2910.51 and 2988.93 were detected in MALDI-TOF MS linear mode (Table 1). Together these data are consistent with the presence of amino acids 2629-2653 of DNA-PKcs containing a single phosphorylation site (predicted mass, 2907.1) and a doubly phosphorylated species (predicted mass, 2987.1). From these data we propose that phosphopeptide $\mathrm{P}_{3}$ corresponds to amino acids 2629-2653 of DNA-PKcs, in which both $\mathrm{Thr}^{2638}$ and Thr ${ }^{2647}$ are phosphorylated (Table 1). Thus phosphopeptide $\mathrm{P}_{3}$ contains the same phosphorylation sites as $\mathrm{P}_{2}$, but differs from $\mathrm{P}_{2}$ in that the Arg at position 2636 of DNA-PKcs was not cleaved by trypsin.
Peak $\mathrm{P}_{4}$ was also analysed by phosphoamino acid analysis, solid-phase Edman sequencing and MS. $\mathrm{P}_{4}$ contained phosphoserine and phosphothreonine (Table 1, and results not shown), and radioactivity was released predominantly at positions 10,11 and 14 (Figure 2D). Ions of average mass 2392.737 and 2472.748 were observed by MALDI-TOF MS linear mode (Table 1). A tryptic peptide containing amino acids 2599-2619 of DNA-PKcs and phosphorylated at one site is predicted to have a mass of 2392.62, whereas the doubly phosphorylated form of the same peptide is predicted to have a mass of 2472.62. Together these data are consistent with phosphorylation of $\mathrm{Thr}^{2609}$ and $\mathrm{Ser}^{2612}$ in the tryptic peptide beginning at amino acid 2599 and ending at amino acid 2619 (Table 1). It is possible that additional phosphopeptides are present in $\mathrm{P}_{4}$; however, we have not identified them further at this time.

Like $\mathrm{P}_{4}, \mathrm{P}_{5}$ was also phosphorylated on serine and threonine (Table 1, and results not shown). The major position of radioactivity release following Edman sequencing occurred at cycles 11 and 14 (Figure 2E). MALDI-TOF analysis revealed a peak of mass 2390.97 (Table 1). This corresponds well to a mass of 2391.16 that is predicted to occur from the peptide beginning at amino acid 2599 and ending at amino acid 2619, containing one phosphate group and one modified methionine (Table 1). We conclude that $\mathrm{P}_{5}$ is also derived from amino acids 2599-2619 of DNA-PKcs, and is phosphorylated predominantly on $\mathrm{Thr}^{2609} . \mathrm{P}_{4}$ and $\mathrm{P}_{5}$ were poorly resolved on HPLC (Figure 1). It is likely that the radioactivity released at cycle 14 represents phosphorylation of $\mathrm{Ser}^{2612}$, as observed in Figure 2(D) for peptide $\mathrm{P}_{4}$.

$\mathrm{P}_{6}$ contained only phosphoserine (Table 1 , and results not shown), and radioactive phosphate was released at position 9 (Figure 2F). An ion of average mass 4197.84 was observed on MALDI-TOF MS (linear mode), which is consistent with a peptide corresponding to amino acids 3197-3232 of DNA-PKcs, containing a single phosphate and an oxidized methionine (predicted mass 4197.55; Table 1). We therefore conclude that $P_{6}$ corresponds to amino acids 3197-3232 of DNA-PKcs phosphorylated at $\mathrm{Ser}^{3205}$ (Table 1).

In summary, analysis of HPLC-purified peptides by solidphase sequencing and MS suggests that, in vitro, DNA-PKcs is autophosphorylated at $\mathrm{Thr}^{2609}, \mathrm{Ser}^{2612}, \mathrm{Ser}^{2624}, \mathrm{Thr}^{2638}$, $\mathrm{Thr}^{2647}$ and $\mathrm{Ser}^{3205}$. From the relative abundance of each of the phosphorylated peaks in HPLC (Figure 1), our data suggest that the major site of phosphorylation in DNA-PKcs is $\mathrm{Th}^{2638}\left(\mathrm{P}_{2}\right)$, with $\operatorname{Ser}^{2624}\left(\mathrm{P}_{1}\right)$, Thr ${ }^{2647}\left(\mathrm{P}_{2}\right.$ and $\left.\mathrm{P}_{3}\right), \operatorname{Thr}^{2609}\left(\mathrm{P}_{5}\right), \operatorname{Ser}^{2612}\left(\mathrm{P}_{4}\right)$ and 
A

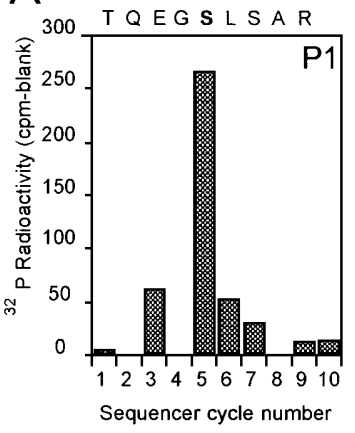

C

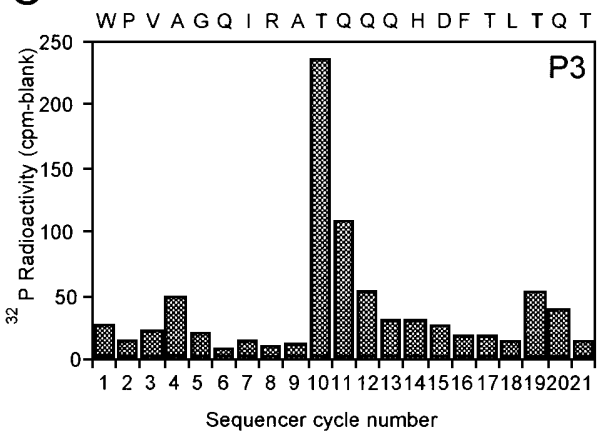

$E$



B

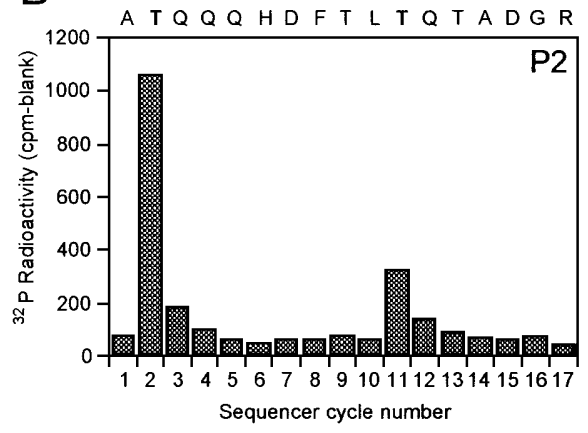

D

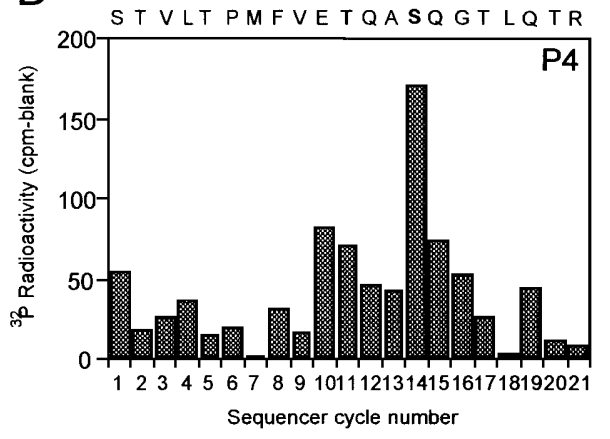

F

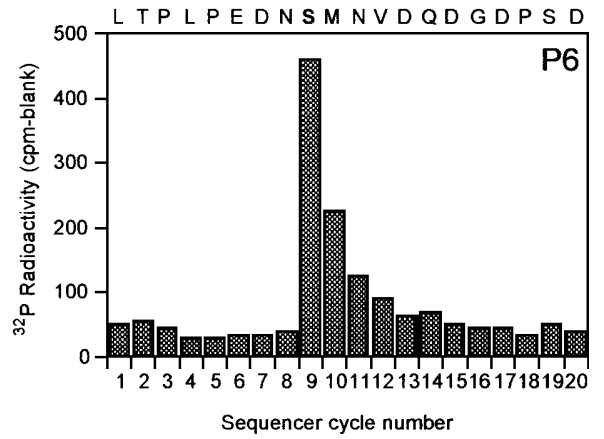

Figure 2 Identification of the autophosphorylation sites in ${ }^{32}$ P-labelled DNA-PKcs peptides

Aliquots of the major ${ }^{32} \mathrm{P}$-labelled peptides derived from phosphorylated DNA-PKcs (Figure 1) were covalently coupled to a Sequelon arylamine membrane and analysed on an Applied Biosystems 476A sequenator. ${ }^{32} \mathrm{P}$ radioactivity was measured after each cycle of Edman degradation. In combination with MALDI-TOF MS, database searching against predicted DNA-PKcs tryptic peptides and phosphoamino acid analysis (Table 1); this enabled the identification of the sites of phosphorylation in each of the peptides. The putative amino acid sequence of each peptide, deduced from a combination of phosphoamino acid analysis, MS and solid-phase sequencing, is indicated on the top of each panel. Phosphopeptide peaks $P_{1}-P_{6}$ are as in Figure 1.

$\operatorname{Ser}^{3205}\left(\mathrm{P}_{6}\right)$ representing less-abundant in vitro phosphorylation sites. Interestingly, five of the identified sites lie in a cluster of 38 amino acids corresponding to positions 2609-2647 of DNA$\mathrm{PKcs}$. This region of the protein is distal to the $\mathrm{C}$-terminal kinase domain, which located in the last 500 amino acids of the 4127amino-acid polypeptide. The function of this region of the protein is not known; however, it is interesting to note that four of the identified phosphorylated amino acids $\left(\mathrm{Thr}^{2609}, \mathrm{Thr}^{2638}\right.$, $\mathrm{Thr}^{2647}$ and $\mathrm{Ser}^{3205}$ ) are conserved between human, mouse, horse, dog, chicken and Xenopus laevis (Table 2). Ser ${ }^{2624}$ is conserved in human, horse, dog and chicken, but not mouse (Table 2). This suggests that these amino acids are important for the function of DNA-PKcs. Although several of the identified sites were present as SQ or TQ motifs ( $\mathrm{Thr}^{2609}, \mathrm{Ser}^{2612}, \mathrm{Thr}^{2638}$ and $\mathrm{Thr}^{2647}$ ), others did not conform to the 'classical' DNA-PKcs consensus (SQ/TQ motif). Rather, these sites, $\operatorname{Ser}^{2624}$ (GSLSAR) and $\mathrm{Ser}^{3205}$ (DNSMNV), conform to the Ser hydrophobic amino acid DNAPK sites previously identified in $\mathrm{Ku} 70$ and $\mathrm{Ku} 80$ [19].

\section{Characterization of phosphospecific antibodies to the identified DNA-PKcs phosphorylation sites}

To determine whether any of these sites were phosphorylated in vivo, we generated a panel of phosphospecific antibodies corresponding to $\mathrm{Thr}^{2609}, \mathrm{Ser}^{2612}, \mathrm{Th}^{2638}$ and $\mathrm{Thr}^{2647}$ (see the 


\section{Table 2 Conservation of in vitro and in vivo DNA-PKcs phosphorylation sites in vertebrate species}

The following DNA-PKcs amino acid sequences were obtained from NCBI: human (accession number P78527); horse (accession number AAL40980); dog (accession number AAL40979); mouse (accession number P97313), chicken (accession number BAB91148); frog (Xenopuslaevis, accession number BAA36690). The numbering at the top of each block of sequence corresponds to the identified phosphorylation sites in human DNA-PKcs (P78527). Amino acids that are conserved between all 6 species are indicated in bold.

\begin{tabular}{|c|c|c|c|}
\hline & $\mathrm{T}^{2609} \mathrm{~S}^{2}$ & $\mathbf{s}^{2534}$ & $T^{2647}$ \\
\hline human & \multicolumn{3}{|c|}{ WRFRSTVLTPMFVETQASQGTLQTRTQEGSLSARWPVAGQIRATQQQHDFTLTQTADGR } \\
\hline hors & \multicolumn{3}{|c|}{ WRFRSTVLTPMFIETQASQSALQTRTQEGSLSARGVMTGQIRATQQQYDFTPTQNTDGR } \\
\hline dog & \multicolumn{3}{|c|}{ WRFRSTVLTPUF I MTQASQSTLQTRTQERSLPAQGVMARQIRATQQQYDFTPTQTADGR } \\
\hline mouse & \multirow{2}{*}{\multicolumn{3}{|c|}{$\begin{array}{l}\text { WRFRSTVLTPUF IETQAS PSILHTQTQEGPLSDQRQKPGQVRATQQQYDFTPTQASVER } \\
\text { WRYRSTMLTPUF VITQASQSTNRNSSQERSLSISGSVGGRVRATQRQYEFTPTQNVSGR }\end{array}$}} \\
\hline chick & & & \\
\hline frog & WRFRSSVLTPAFVETQLSQSMC & TIEADEPIGGQLRATQQ & PTQNIGGI \\
\hline
\end{tabular}

\begin{tabular}{ll} 
& \multicolumn{1}{c}{$\mathbf{s}^{\mathbf{3 2 0 5}}$} \\
human & PLPE-DNSMNVDQDGDPSDRMEVQ \\
horse & IPPD-DHSMNTDGDEDSSDRMKVQ \\
dog & LPLG-DHSLSMDEERDSSDKMEVQ \\
mouse & APSG-DHSMSVDEDEESIDR-EVY \\
chicken & CDKAND-SMEVDEESSVGDQMEVD \\
frog & PQLV-DESMEVDDLADGNEAMEVD
\end{tabular}

Materials and methods section for details). As discussed above, five of the identified phosphorylation sites reside in a region of 38 amino acids within the 4127-amino-acid sequence of DNA-PKcs. Also present in this region was another TQ motif $\left(\mathrm{Thr}^{2620}\right)$ that was not identified in the experiments described above. In order to test whether this site might also be phosphorylated in DNAPKcs, we also generated a phosphospecific antibody to $\mathrm{Thr}^{2620}$ (see the Materials and methods section for details). Phosphospecific antibodies to $\operatorname{Ser}^{2624}$ and $\mathrm{Ser}^{3205}$ are currently being generated.

The phosphospecific antibodies were then used to characterize phosphorylation of DNA-PKcs in vitro. The DNA-PK enzyme is only active when assembled on DNA. We would therefore predict that DNA-PKcs would only be phosphorylated in the presence of added DNA. To test this, purified DNA-PKcs and $\mathrm{Ku}$ were incubated in the presence of MgATP in either the absence (Figure 3, lane 1) or presence (Figure 3, lanes 2 and 3) of sonicated calf thymus DNA. Samples were then run on SDS/PAGE and probed with phosphospecific antibodies to $\mathrm{Thr}^{2609}, \mathrm{Ser}^{2612}, \mathrm{Thr}^{2620}, \mathrm{Thr}^{2638}$ or $\mathrm{Thr}^{2647}$ as indicated (Figure 3). The upper immunoblots in each panel correspond to immunoblots that were incubated with the phosphospecific antibodies, while the lower blots in each panel represent the same blots after stripping and reprobing with $\mathrm{mAb} 42-27$. Immunoblots shown on the upper left-hand side of each panel were incubated with the phosphospecific antibody in the presence of the corresponding dephosphopeptide, while those in the upper right-hand panel were incubated with the phosphospecific antibody in the presence of the appropriate blocking phosphopeptide. These results show that DNA-PKcs is phosphorylated in vitro at $\mathrm{Thr}^{2609}$, $\mathrm{Ser}^{2612}$, $\mathrm{Thr}^{2620}$, $\mathrm{Thr}^{2638}$ and $\mathrm{Thr}^{2647}$, that the antibodies generated are indeed specific for the phosphorylated forms of DNA-PKcs (as the signal is ablated by incubation with the blocking peptide). Additionally, each phosphospecific antibody was specific for its specific phosphorylation site, as the phosphopeptide corresponding to a different site did not ablate the signal (results not shown). Although $\mathrm{Thr}^{2620}$ was not identified directly using HPLC and MS, the phosphospecific antibody indicates that it also is an in vitro phosphorylation site (Figure $3 \mathrm{C}$ ). The data also show that phosphorylation at each site is DNA-dependent. As expected, no signal was observed when samples containing DNA-PKcs, $\mathrm{Ku}$ and sonicated calf thymus DNA were incubated in the absence of added ATP (results not shown). DNA-PKcs was also phosphorylated at each site in the presence of single-stranded M13 DNA and linearized plasmid double-stranded DNA (results not shown).

DNA-PKcs is a member of the phosphoinositide 3-kinase-like family of serine/threonine protein kinases, and, as such, its protein kinase activity is inhibited by the wortmannin $[6,10,11]$. When $1 \mu \mathrm{M}$ wortmannin was added to reactions containing DNA-PKcs, Ku, DNA and MgATP, phosphorylation at each site was abolished (Figure 4, lane 2). Other members of the phosphoinositide 3-kinase-like family of protein kinases are active in manganese, rather than magnesium [30-34], and we have previously shown that DNA-PK is also active in the presence of manganese [33]. We therefore carried out in vitro phosphorylation reactions in the presence of manganese instead of magnesium. Phosphorylation at $\mathrm{Thr}^{2609}, \mathrm{Ser}^{2612}$, $\mathrm{Thr}^{2620}$, $\mathrm{Thr}^{2638}$ and $\mathrm{Thr}^{2647}$ also occurred in the presence of manganese, and, as with magnesium, was inhibited by wortmannin (Figure 4, lanes 3 and 4).

We and others have shown previously that highly purified DNA-PKcs has very weak protein kinase activity in the absence of $\mathrm{Ku}[6,21,35,36]$. These low levels are likely due to either traces of $\mathrm{Ku}$ in the purified DNA-PKcs or low basal activity of DNA-PKcs. When purified DNA-PKcs was incubated with DNA and MgATP in the absence of $\mathrm{Ku}$, phosphorylation at each of the identified sites was observed, but at a reduced level (Figure 4, lane 5). Thus phosphorylation at $\mathrm{Thr}^{2609}, \mathrm{Ser}^{2612}$, $\mathrm{Thr}^{2620}, \mathrm{Thr}^{2638}$ and $\mathrm{Thr}^{2647}$ occurs in the presence of either manganese or magnesium, is inhibited by wortmannin, and is decreased in the absence of $\mathrm{Ku}$.

\section{Phosphorylation of DNA-PKcs in vivo}

We have previously shown that DNA-PKcs, Ku70 and Ku80 are phosphorylated in vivo in cells that have been treated with the protein phosphatase inhibitor okadaic acid [23]. In order to 


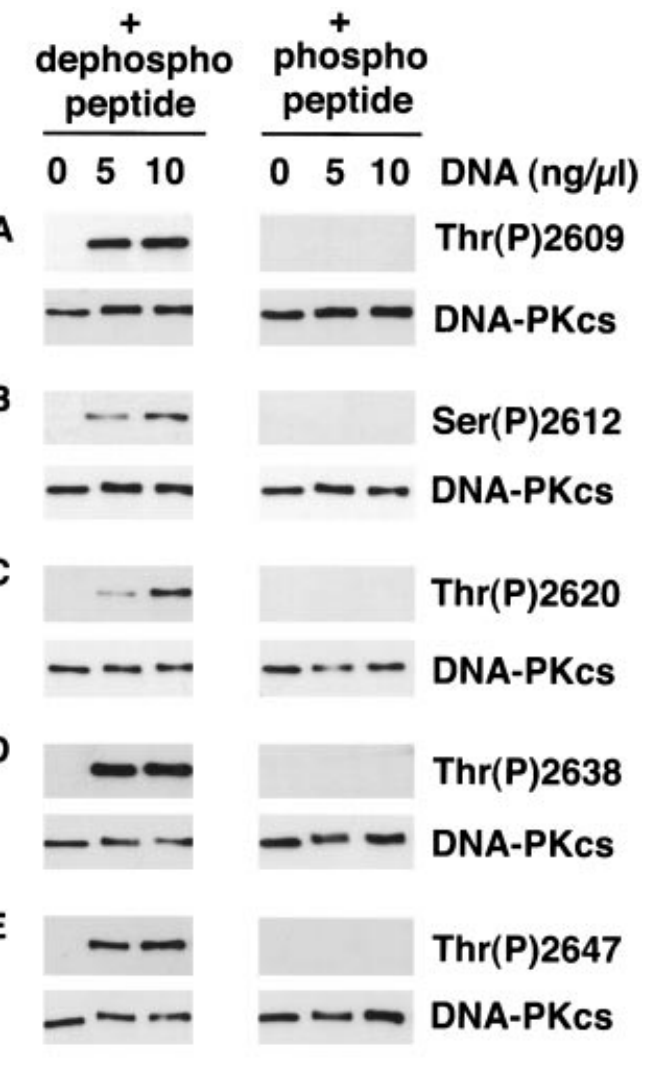

$\begin{array}{llllll}1 & 2 & 3 & 1 & 2 & 3\end{array}$

Figure 3 The phosphospecific antibodies recognize autophosphorylated DNA-PKcs in vitro

DNA-PKcs (100 ng) and Ku (30 ng) were incubated under standard assay conditions as described in the Materials and methods section, with and without the addition of sonicated calf thymus DNA as indicated. All samples contained MgATP at a final concentration of $2.5 \mathrm{mM}$. Samples were analysed by SDS/PAGE followed by immunoblot using phosphospecific antibodies raised against phosphorylated $\mathrm{Thr}^{2609}, \mathrm{Ser}^{2612}, \mathrm{Thr}^{2620}, \mathrm{Thr}^{2638}$ or $\mathrm{Thr}^{2647}$ as indicated in $(\mathbf{A})-(\mathbf{E})$. For each experiment, immunoblots were either incubated with the phosphospecific antibody in the presence of the respective dephosphopeptide (upper left of each panel), or with the phosphospecific antibody in the presence of the respective phosphopeptide (upper right of each panel). After probing with the phosphospecific antibody, each immunoblot was stripped and incubated with a non-phosphospecific antibody to DNA-PKcs (mAb 42-27) (lower right- and left-hand sections of each panel).

determine if DNA-PKcs was phosphorylated in vivo at the identified in vitro phosphorylation sites, cells were treated with okadaic acid for 0,2 or $3 \mathrm{~h}$, and extracts were prepared and probed by immunoblot using the phosphospecific antibodies as indicated in Figures 3 and 4. DNA-PKcs was found to be phosphorylated at $\mathrm{Thr}^{2609}, \mathrm{Ser}^{2612}, \mathrm{Thr}^{2638}$ and $\mathrm{Thr}^{2647}$ in okadaic acid-treated cells (Figure 5). However, no phosphorylation of $\mathrm{Thr}^{2620}$ was detected under these conditions (results not shown).

\section{DISCUSSION}

Using protein chemistry and MS, we have identified the major autophosphorylation sites in DNA-PKcs. In vitro, DNA-PKes is phosphorylated at $\mathrm{Thr}^{2609}, \mathrm{Ser}^{2612}, \mathrm{Ser}^{2624}, \mathrm{Thr}^{2638}, \mathrm{Thr}^{2647}$ and $\mathrm{Ser}^{3205}$, with $\mathrm{Thr}^{2638}$ likely representing the most abundant site. Phosphorylation at each site was confirmed using phosphospecific antibodies, was dependent on the presence of added DNA, and was inhibited by wortmannin. Using phosphospecific anti-



Figure 4 Autophosphorylation at each site is inhibited by wortmannin

DNA-PKcs (100 ng) and/or Ku (30 ng) were incubated and processed exactly as described in Figure 3 except for the following changes. Lanes 2, $1 \mu \mathrm{M}$ wortmannin was added to samples prior to addition of MgATP; lanes 3 and 4, samples were as in lanes 1 and 2, except that $10 \mathrm{mM} \mathrm{Mn}^{2+}$ was added to reactions instead of $10 \mathrm{mM} \mathrm{Mg}^{2+}$. Lane 5, the sample contained DNA-PKcs and MgATP but not Ku. All reactions contained $10 \mu \mathrm{g} / \mathrm{ml}$ sonicated calf thymus DNA.

bodies, $\mathrm{Thr}^{2620}$ was also identified as an in vitro DNA-PKcs phosphorylation site.

Interestingly, $\mathrm{Thr}^{2609}, \mathrm{Ser}^{2612}, \mathrm{Thr}^{2620}, \mathrm{Ser}^{2624}, \mathrm{Thr}^{2638}$ and $\mathrm{Thr}^{2647}$ are clustered in a 38-amino-acid region, which represents less than $1 \%$ of the total amino acids in DNA-PKcs. Also, all of the sites occur distant to the C-terminal catalytic domain of DNA-PKcs. Moreover, $\mathrm{Thr}^{2609}, \mathrm{Ser}^{2612}$, $\mathrm{Thr}{ }^{2638}, \mathrm{Thr}^{2647}$ and $\mathrm{Ser}^{3205}$ are conserved in DNA-PKcs from human [10], mouse [37], dog [38], horse [39], chicken [40] and X. laevis [41] (Table 2). This high degree of conservation strongly suggests that phosphorylation of DNA-PKcs at these sites is important for DNAPK function. Although we cannot exclude the possibility that other sites are phosphorylated in DNA-PKcs, this short region of DNA-PKcs appears to contain the major in vitro phosphorylation sites.

DNA-PKcs is required for DNA DSB repair via the process of NHEJ, and the catalytic activity of DNA-PKcs is required for its function [12,13]. Biochemical models suggest that DNA-PK assembles at the ends of DNA to form the active protein kinase complex. We therefore propose that the physiological substrates 


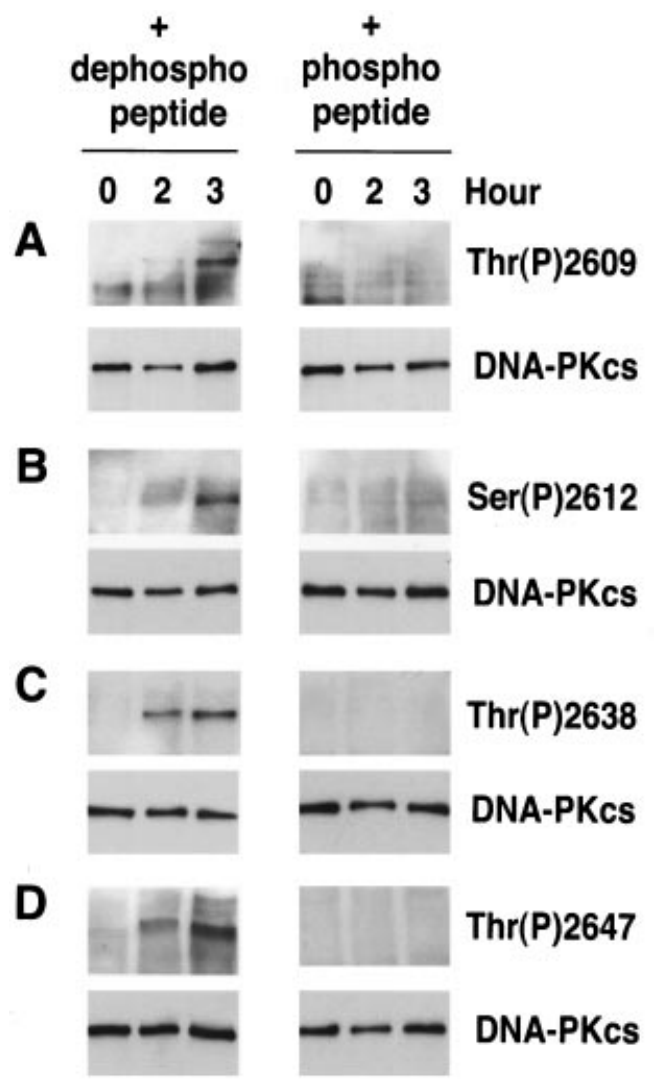

Figure 5 Okadaic acid induces phosphorylation of DNA-PKcs in vivo

Human lymphoblastoid cells (BT) were incubated with okadaic acid ( $1 \mu \mathrm{M})$ and harvested after 0,2 or $3 \mathrm{~h}$. Whole cell extracts were prepared as described in the Materials and methods section and $100 \mu \mathrm{g}$ of protein was analysed on SDS/PAGE followed by immunoblot using phosphospecific antibodies followed by mAb 42-27, exactly as described in Figure 3.

of DNA-PK are also present at the site of the DNA DSB. We have previously shown that DNA-PKcs, Ku70 and Ku80 undergo autophosphorylation in vitro, and that autophosphorylation results in the loss of DNA-PK protein kinase activity and dissociation of DNA-PKcs from the DNA-bound $\mathrm{Ku}$ complex [21-23]. We propose that after assembly of the active DNA-PK complex at the DNA DSB, DNA-PK undergoes autophosphorylation, which results in the release of phosphorylated DNA-PKcs from the complex. Another prediction of this model is that protein phosphatases are required to dephosphorylate the phosphorylated inactive DNA-PKes to allow DNA-PKcs to interact with $\mathrm{Ku}$ in a subsequent round of the cycle. We have previously shown that, in vitro, protein phosphatases can remove the phosphate groups from autophosphorylated inactive DNAPKcs and restore DNA-PK protein kinase activity [23]. Moreover, incubation of cells with the protein phosphatase inhibitor, okadaic acid, increased the in vivo phosphorylation state of DNA-PKcs and reduced its protein kinase activity [23]. We therefore propose that, by inhibiting protein phosphatases, okadaic acid maintains DNA-PKcs in a more highly phosphorylated, inactive state. Here we show that four of the identified in vitro phosphorylation sites in DNA-PKcs $\left(\mathrm{Thr}^{2609} \mathrm{Ser}^{2612}\right.$, $\mathrm{Thr}^{2638}$ and $\mathrm{Thr}^{2647}$ ) are phosphorylated in vivo in okadaic acidtreated cells. As observed previously in cells that were labelled metabolically with $\left[{ }^{32} \mathrm{P}\right] \mathrm{P}_{\mathrm{i}}$, very little in vivo phosphorylation of DNA-PKcs was observed in the absence of okadaic acid [23].
These data suggest that DNA-PKcs is rapidly dephosphorylated in vivo in the absence of protein phosphatase inhibitors.

From our model, we predict that DNA-PKcs would be phosphorylated in vivo only when bound to the site of the DNA DSB. Treatment of cells with DNA-damaging agents, such as ionizing radiation, which produce DNA DSBs, would therefore be expected to induce a transient increase in DNA-PKcs phosphorylation at the sites of the DNA DSBs. To date we have been unable to detect phosphorylation of DNA-PKcs in nuclear extracts from irradiated cells, either by immunoblot using phosphospecific antibodies directly, or by immunoprecipitation with DNA-PKcs-specific antibodies, followed by immunoblot with phosphospecific antibodies. It has been estimated that the number of DNA DSBs produced in human cells by ${ }^{137} \mathrm{Cs}$ ionizing radiation is 2-8 sites/billion base pairs per Gy [42]. Since the human genome contains approx. 3 billion base pairs, 1 Gy of ionizing radiation would be predicted to produce 6-24 DNA DSBs per nucleus. Assuming that two molecules of DNA-PKcs assemble at each DNA DSB, 1 Gy of radiation would be expected to result in no more than 50 phosphorylated DNA-PKcs molecules per nucleus. The number of $\mathrm{Ku}$ molecules in the cell has been estimated at approx. 400000 [43]. We estimate that DNA$\mathrm{PKcs}$ is, at most, half as abundant as $\mathrm{Ku}$; thus there are likely to be less than 200000 molecules of DNA-PKcs in the nucleus of a human cell. Thus less than $0.05 \%$ of the total population of DNA-PKes is likely to undergo phosphorylation under these conditions. It is therefore likely that the signal from in vivophosphorylated DNA-PKcs was below the detection limits of our antibodies. Alternatively, other methods of detection such as immunofluorescence will be required to see DNA-PKcs phosphorylation in vivo. Recently, Chen and colleagues [44] identified $\mathrm{Thr}^{2609}$ as an in vitro and in vivo DNA-PKes phosphorylation site. Moreover, mutation of $\mathrm{Thr}^{2609}$ to Ala resulted in radiation sensitivity and impaired rejoining of DNA DSBs [44]. Preliminary results suggest that mutation of other DNA-PKes phosphorylation identified in this study have a similar phenotype (K. Meek and S. P. Lees-Miller, unpublished work). Thus in vivo phosphorylation of DNA-PKes at one or more of the autophosphorylation sites identified in this study is likely to be required for DNA-PKcs function in NHEJ.

We thank Dr Jane Leitch and Diagnostics Scotland for making the phosphospecific antibodies, Dr Graham Bloomberg for advice on phosphospecific peptides, and Ruiqiong Ye for assistance with cell culture. We are also very grateful to Dr David Chen (Lawrence Berkeley Laboratory, Berkeley, CA, U.S.A.) for communicating his results to us prior to publication. Work in S. P. L.-M.'s laboratory was supported by a grant (no. 13639) from the Canadian Institutes of Health Research. Work in D.R.A.'s laboratory was funded by the Medical Research Council (U.K.), Diabetes UK, Association for International Cancer Research and the pharmaceutical companies supporting the Division of Signal Transduction Therapy Unit in Dundee (AstraZeneca, Boehringer Ingelheim, GlaxoSmithKline, Novo-Nordisk and Pfizer). P.D. was supported by a post-doctoral fellowship of the Alberta Heritage Foundation for Medical Research. A. A. G. is supported by a graduate studentship from the Alberta Heritage Foundation for Medical Research. S.P.L.-M. is a Scientist of the Alberta Heritage Foundation for Medical Research and an Investigator of the Canadian Institutes for Health Research.

\section{REFERENCES}

1 Norbury, C. J. and Hickson, I. D. (2001) Cellular responses to DNA damage. Annu. Rev. Pharmacol. Toxicol. 41, 367-401

2 van Gent, D. C., Hoeijmakers, J. H. and Kanaar, R. (2001) Chromosomal stability and the DNA double-stranded break connection. Nat. Rev. Genet. 2, 196-206

3 Moshous, D., Li, L., Chasseval, R., Philippe, N., Jabado, N., Cowan, M. J., Fischer, A. and de Villartay, J.P. (2000) A new gene involved in DNA double-strand break repair and $V(D) J$ recombination is located on human chromosome 10p. Hum. Mol. Genet. 9. 583-588 
4 Moshous, D., Callebaut, I., de Chasseval, R., Corneo, B., Cavazzana-Calvo, M. Le Deist, F., Tezcan, I., Sanal, O., Bertrand, Y., Philippe, N. et al. (2001) Artemis, a novel DNA double-strand break repair/ $V$ (D)J recombination protein, is mutated in human severe combined immune deficiency. Cell 105, 177-186

5 Ma, Y., Pannicke, U., Schwarz, K. and Lieber, M. R. (2002) Hairpin opening and overhang processing by an Artemis/DNA-dependent protein kinase complex in nonhomologous end joining and V(D)J recombination. Cell 108, 781-794

6 Smith, G. C. and Jackson, S. P. (1999) The DNA-dependent protein kinase. Genes Dev. 13, 916-934

7 Lee, K. J., Huang, J., Takeda, Y. and Dynan, W. S. (2000) DNA ligase IV and XRCC4 form a stable mixed tetramer that functions synergistically with other repair factors in a cell-free end-joining system. J. Biol. Chem. 275, 34787-34796

8 Baumann, P. and West, S. C. (1998) DNA end-joining catalyzed by human cell-free extracts. Proc. Natl. Acad. Sci. U.S.A. 95, 14066-14070

9 Chen, S., Inamdar, K. V., Pfeiffer, P., Feldmann, E., Hannah, M. F., Yu, Y., Lee, J. W., Zhou, T., Lees-Miller, S. P. and Povirk, L. F. (2001) Accurate in vitro end joining of a DNA double strand break with partially cohesive 3'-overhangs and 3'phosphoglycolate termini: effect of Ku on repair fidelity. J. Biol. Chem. 276, 24323-24330

10 Hartley, K. O., Gell, D., Smith, G. C., Zhang, H., Divecha, N., Connelly, M. A., Admon, A., Lees-Miller, S. P., Anderson, C. W. and Jackson, S. P. (1995) DNA-dependent protein kinase catalytic subunit: a relative of phosphatidylinositol 3-kinase and the ataxia telangiectasia gene product. Cell $\mathbf{8 2}, 849-856$

11 Izzard, R. A., Jackson, S. P. and Smith, G. C. (1999) Competitive and noncompetitive inhibition of the DNA-dependent protein kinase. Cancer Res. 59, 2581-2586

12 Kurimasa, A., Kumano, S., Boubnov, N. V., Story, M. D., Tung, C. S., Peterson, S. R. and Chen, D. J. (1999) Requirement for the kinase activity of human DNA-dependent protein kinase catalytic subunit in DNA strand break rejoining. Mol. Cell. Biol. 19, 3877-3884

13 Kienker, L. J., Shin, E. K. and Meek, K. (2000) Both V(D)J recombination and radioresistance require DNA-PK kinase activity, though minimal levels suffice for V(D)J recombination. Nucleic Acids Res. 28, 2752-2761

14 Lees-Miller, S. P. and Anderson, C. W. (1989) The human double-stranded DNAactivated protein kinase phosphorylates the 90-kDa heat-shock protein, hsp90 $\alpha$ at two $\mathrm{NH}_{2}$-terminal threonine residues. J. Biol. Chem. 264, 17275-17280

15 Lees-Miller, S. P., Sakaguchi, K., Ullrich, S. J., Appella, E. and Anderson, C. W. (1992) Human DNA-activated protein kinase phosphorylates serines 15 and 37 in the amino-terminal transactivation domain of human p53. Mol. Cell. Biol. 12, 5041-5049

16 Bannister, A. J., Gottlieb, T. M., Kouzarides, T. and Jackson, S. P. (1993) c-Jun is phosphorylated by the DNA-dependent protein kinase in vitro; definition of the minimal kinase recognition motif. Nucleic Acids Res. 21, 1289-1295

17 O'Neill, T., Dwyer, A. J., Ziv, Y., Chan, D. W., Lees-Miller, S. P., Abraham, R. H., Lai, J. H., Hill, D., Shiloh, Y., Cantley, L. C. and Rathbun, G. A. (2000) Utilization of oriented peptide libraries to identify substrate motifs selected by ATM. J. Biol. Chem. 275, 22719-22727

18 Anderson, C. W. and Lees-Miller, S. P. (1992) The nuclear serine/threonine protein kinase DNA-PK. Crit. Rev. Eukaryot. Gene Expr. 2, 283-314

19 Chan, D. W., Ye, R., Veillette, C. J. and Lees-Miller, S. P. (1999) DNA-dependent protein kinase phosphorylation sites in Ku 70/80 heterodimer. Biochemistry $\mathbf{3 8}$, 1819-1828

20 Lees-Miller, S. P., Chen, Y. R. and Anderson, C. W. (1990) Human cells contain a DNA-activated protein kinase that phosphorylates simian virus $40 \mathrm{~T}$ antigen, mouse p53, and the human Ku autoantigen. Mol. Cell. Biol. 10, 6472-6481

21 Chan, D. W. and Lees-Miller, S. P. (1996) The DNA-dependent protein kinase is inactivated by autophosphorylation of the catalytic subunit. J. Biol. Chem. 271, 8936-8941

22 Merkle, D., Douglas, P., Moorhead, G. B. G., Leonenko, Z., Yu, Y., Cramb, D., BazettJones, D. P. and Lees-Miller, S. P. (2002) The DNA-dependent protein kinase interacts with DNA to form a protein-DNA complex that is disrupted by phosphorylation. Biochemistry, DOI 10.1021/bi0263558

23 Douglas, P., Moorhead, G. B., Ye, R. and Lees-Miller, S. P. (2001) Protein phosphatases regulate DNA-dependent protein kinase activity. J. Biol. Chem. 276, 18992-18998

Received 25 June 2002/12 August 2002; accepted 19 August 2002

Published as BJ Immediate Publication 19 August 2002, DOI 10.1042/BJ20020973
24 Gell, D. and Jackson, S. P. (1999) Mapping of protein-protein interactions within the DNA-dependent protein kinase complex. Nucleic Acids Res. 27, 3494-3502

25 Walker, J. R., Corpina, R. A. and Goldberg. J. (2001) Structure of the Ku heterodimer bound to DNA and its implications for double-strand break repair. Nature (London) 412, 607-614

26 Sapkota, G. P., Boudeau, J., Deak, M., Kieloch, A., Morrice, N. and Alessi, D. R. (2002) Identification and characterization of four novel phosphorylation sites (Ser31, Ser325, Thr336 and Thr366) on LKB1/STK11, the protein kinase mutated in PeutzJeghers cancer syndrome. Biochem. J. 362, 481-490

27 Alessi, D. R., Gomez, N., Moorhead, G., Lewis, T., Keyse, S. M. and Cohen, P. (1995) Inactivation of p42 MAP kinase by protein phosphatase $2 \mathrm{~A}$ and a protein tyrosine phosphatase, but not CL100, in various cell lines. Curr. Biol. 5, 283-295

28 Song, Q., Lees-Miller, S. P., Kumar, S., Zhang, Z., Chan, D. W., Smith, G. C., Jackson, S. P., Alnemri, E. S., Litwack, G., Khanna, K. K. and Lavin, M. F. (1996) DNA-dependent protein kinase catalytic subunit: a target for an ICE-like protease in apoptosis. EMBO J. 15, 3238-3246

29 Ye, R., Bodero, A., Zhou, B. B., Khanna, K. K., Lavin, M. F. and Lees-Miller, S. P. (2001) The plant isoflavenoid genistein activates p53 and Chk2 in an ATM-dependent manner. J. Biol. Chem. 276, 4828-4833

30 Banin, S., Moyal, L., Shieh, S., Taya, Y., Anderson, C. W., Chessa, L., Smorodinsky, N. I., Prives, C., Reiss, Y., Shiloh, Y. and Ziv, Y. (1998) Enhanced phosphorylation of p53 by ATM in response to DNA damage. Science 281, 1674-1677

31 Canman, C. E., Lim, D. S., Cimprich, K. A., Taya, Y., Tamai, K., Sakaguchi, K., Appella, E., Kastan, M. B. and Siliciano, J. D. (1998) Activation of the ATM kinase by ionizing radiation and phosphorylation of p53. Science 281, 1677-1679

32 Mallory, J. C. and Petes, T. D. (2000) Protein kinase activity of Tel1p and Mec1p, two Saccharomyces cerevisiae proteins related to the human ATM protein kinase. Proc. Natl. Acad. Sci. U.S.A. 97, 13749-13754

33 Chan, D. W., Son, S. C., Block, W., Ye, R., Khanna, K. K., Wold, M. S., Douglas, P., Goodarzi, A. A., Pelley, J., Taya, Y. et al. (2000) Purification and characterization of ATM from human placenta. A manganese-dependent, wortmannin-sensitive serine/threonine protein kinase. J. Biol. Chem. 275, 7803-7810

34 Abraham, R. T. (2001) Cell cycle checkpoint signaling through the ATM and ATR kinases. Genes Dev. 15, 2177-2196

35 Gottlieb, T. M. and Jackson, S. P. (1993) The DNA-dependent protein kinase: requirement for DNA ends and association with Ku antigen. Cell 72, 131-142

36 Lees-Miller, S. P., Godbout, R., Chan, D. W., Weinfeld, M., Day, 3rd, R. S., Barron, G. M. and Allalunis-Turner, J. (1995) Absence of p350 subunit of DNA-activated protein kinase from a radiosensitive human cell line. Science 267, 1183-1185

37 Araki, R., Fujimori, A., Hamatani, K., Mita, K., Saito, T., Mori, M., Fukumura, R., Morimyo, M., Muto, M., Itoh, M. et al. (1997) Nonsense mutation at Tyr-4046 in the DNA-dependent protein kinase catalytic subunit of severe combined immune deficiency mice. Proc. Natl. Acad. Sci. U.S.A. 94, 2438-2443

38 Ding, Q., Bramble, L., Yuzbasiyan-Gurkan, V., Bell, T. and Meek, K. (2002) DNA-PKcs mutations in dogs and horses: allele frequency and association with neoplasia. Gene 283, 263-269

39 Shin, E. K., Perryman, L. E. and Meek, K. (1997) A kinase-negative mutation of DNAPK(CS) in equine SCID results in defective coding and signal joint formation. J. Immunol. 158, 3565-3569

40 Fujimori, A., Hashimoto, H., Araki, R., Saito, T., Sato, S., Kasama, Y., Tsutsumi, Y., Mori, M., Fukumura, R., Ohhata, T. et al. (2002) Sequence analysis of 193.4 and $83.9 \mathrm{kbp}$ of mouse and chicken genomic DNAs containing the entire Prkdc (DNA-PKcs) gene. Radiat. Res. 157, 298-305

41 Fujimori, A., Araki, R., Fukumura, R., Ohhata, T., Takahashi, H., Kawahara, A., Tatsumi, K. and Abe, M. (2000) Identification of four highly conserved regions in DNA-PKcs. Immunogenetics 51, 965-973

42 Sutherland, B. M., Bennet, P. V. and Sutherland, J. C. (1996) Double strand breaks induced by low doses of gamma rays or heavy ions: quantitation in nonradioactive human DNA. Anal. Biochem. 239, 53-60

43 Woodgett, J. R. (1993) A kinase with Ku-dos. Curr. Biol. 3, 449-450

44 Chan, D. W., Chen, B. P.-C., Singh, S., Kurimasa, A., Story, M. D., Qin, J. and Chen, D. J. (2002) Autophosphorylation of the DNA-dependent protein kinase catalytic subunit is required for rejoining of DNA double-strand breaks. Genes Dev. 16, 2333-2338 